\title{
Correspondence
}

\section{Epidural anaesthesia: concerns regarding informed consent}

\section{To the Editor:}

The traditional position of the law as it relates to consent has been that of upholding the professional standard; i.e., the physician is required to tell the patient what any other reasonable physician would tell under the same circumstances. More recently, out of respect for the patient's right to selfdetermination, the emphasis has shifted to the reasonable person standard; i.e., the physician is obliged to tell that which any reasonable patient in the same circumstance would want to know in order to make an informed decision about treatment.

Relating such information to the practice of anaesthesia is somewhat difficult. The guidelines published jointly by the Ontario Hospital Association and the Canadian Medical Protective Association in fact indicate that specific consent for anaesthesia is not strictly required in Ontario, ${ }^{1}$ since it is implied in the surgical consent. The rationale seems to centre around the issues of "choice," and since the surgical patient has little choice but to have anaesthesia with the surgical procedure, there is less emphasis on the need for consent. One group, however, who clearly do have a choice are obstetrical patients. Since the courts stress that where there are alternatives to any therapy being offered, the physician is under increased obligation to present the benefits and risks of each alternative ${ }^{2}$ anaesthetists offering epidurals would be wise to give careful consideration to the rights of their patients.

A questionnaire was randomly distributed at the Canadian Anaesthetists' Society meeting in Toronto, June 1985, asking anaesthetists to identify, from a list, those complications of epidural anaesthesia that they feel should ideally be understood by their patients anticipating vaginal delivery, and to rate the importance of each on a scale of $1-5$ ( 5 being of maximum importance). They were then asked whether they, in practice, discuss these same complications with their patients routinely, occasionally, or never. Further questions involved basic demographic information, impressions of the general level of understanding prior to labour, and opinions on when and by whom a presentation of the benefits and risks should be made.

We received 42 responses from Canadian anaesthetists. The mean number of years in practice was 12.7 (range 1-29), and the mean number of epidurals/month (excluding Caesarian section) was 14.7 (range 1-55). Forty-eight per cent identified at least one complication which they consider to be of great importance (4-5 on the scale), but which they never discuss with their patients; in fact 21 per cent (all from Ontario) identified four or more such complications. Seventy-four per cent feel that their patients are seldom or never adequately informed prior to labour, and over 80 per cent feel that it is primarily the anaesthetists' responsibility to educate the patient, but that it is unrealistic to expect the patient to cope with this information during labour.

The limitations of the questionnaire design and the distribution of the responses preclude sophisticated statistical analysis. However, the data suggest that, since many Canadian anaesthetists consider their patients to be poorly informed to begin with, and since they are not presenting the information during labour, it could be argued that their patients are not giving a truly informed consent for epidural anaesthesia.

Certainly there is a lot of support for the position that a presentation of serious risks to the clearly distressed patient is contrary to the best interests of that patient, and therefore not advisable. ${ }^{1-3}$ However, the rights of the patient do require, if it is at all possible, that the patient be placed in a situation where he/she can make a personal decision regarding medical treatment, ${ }^{3}$ and in most cases this could, with some thought, be accomplished prenatally. As to exactly which risks require disclosure, the courts offer very little guidance; however, the emphasis is on "what risk or cluster of risks a reasonable person would be likely to attach significance to" (information that could perhaps be obtained through a carefully designed patient study) 
It would be valuable to know if the actual risks, presented in context with the benefits, would significantly affect the decision-making process.

Worth considerating also is the statement often quoted that: "Even if a certain risk is a mere possibility which ordinarily need not be disclosed, if its occurrence carries serious consequences, as for example paralysis or death, it must be regarded as a material risk requiring disclosure." "1,4 Adding to the controversy is the belief that the remote possibility of death due to general anaesthesia need not be disclosed since it is considered to be "common knowledge" $" 2,3$ (it is, however, doubtful this same logic could be applied to epidurals). While only one respondent felt his patient should understand the possibility of death, 18/42 scored paralysis a 4 or 5 . Of these respondents only three discuss it "occasionally," one presents it on a consent form, and one during pre-natal lectures.

We feel an examination of these issues is warranted, and invite comments from other concerned anaesthetists.

Patricia Slusarenko, RN

William H. Noble MD FRCPC

Department of Anaesthesia

St. Michael's Hospital

30 Bond Street

Toronto, Ontario

\section{REFERENCES}

1 Consent: What Every Hospital and Physician in Ontario Should Know. Toronto, The Ontario Hospital Association, The Canadian Medical Protective Association, 1983.

2 Miller J. Informed Consent: II. JAMA 1980; 224: 2347-50.

3 Somerville MA. Structuring the issues in informed consent. McGill Law Journal, 1983: 26: 740-808.

4 Dominion Law Reports: Reible vs. Hughes. Supreme Court of Canada, Laskin, C.J.C., Martland, Dickson, Beetz, Estey, McIntyre \& Chouinard J.J., Oct 7, 1980.

\section{Anaesthetic breathing circuit leak from cracked oxygen analyzer sensor connector}

\section{To the Editor:}

The oxygen monitor is now considered an essential part of anaesthesia equipment, as a means of detecting and hopefully preventing hypoxic mixture administration. In our department we have used the Foregger 450 Oxygen Monitor for more than five years and have found it well adapted to our needs. However, part of the assembly has been found to present a hazard. The monitor is supplied with a soft black plastic " $T$ " connector where the oxygen sensor is seated for attachment to the fresh gas port of the anaesthetic gas machine. Between cases the sensor is removed from the $\mathrm{T}$ piece for calibration with air and then reconnected. This removal and reinsertion has a tendency to cause cracks in the connector (see Figure). The cracks may be hard to detect, for two reasons: the sensor and the $T$ piece are both black and the defect usually appears on the fresh gas port side, and is thus hidden from the view of the anaesthetist. The crack in turn may cause a leak of fresh gas flow sufficient to produce hypercarbia when the monitor is used with a Mapleson D circuit with the sensor mounted on the fresh gas outlet.

We noted two cases in which tachycardia, hypertension and ventricular extra-systoles appeared without apparent cause after 90 minutes of anaes-

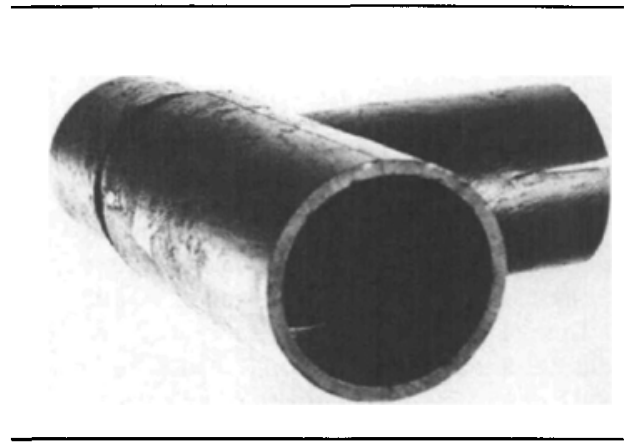

FIGURE Connector with linear crack. 
thesia. Blood gases showed $\mathrm{PaCO}_{2}$ well in excess of 60 torr. A check of the anaesthesia circuit demonstrated a large leak around the sensor due to a damaged $\mathrm{T}$ connector, causing an inadequate fresh gas inflow to the circuit. ${ }^{1}$ All connectors checked subsequently have shown the same defect at one time or another.

\section{Yves Lamarche MD FRCPC}

Centre Hospitalier Universitaire

de Sherbrooke, Sherbrooke, Quebec

\section{REFERENCE}

1 Bain JA, Spoerel WE. Flow requirements for a modified Mapleson D system during cantrolled ventilation. Can Anaesth Soc J 1973; 20: 629-36.

\section{Glycopyrrolate and human plasma cholinesterase}

To the Editor:

I read the paper by Zsigmond et al. ${ }^{1}$ with great interest, as I have been involved in many clinical studies with glycopyrrolate. ${ }^{2}$ The extrapolation of their results to speculation about possible prolongation of the effects of succinylcholine or local anaesthetics is too far fetched. The $\mathrm{IC}_{50}$ of glycopyrrolate on plasma cholinesterase was shown to be $1.0 \mathrm{mM}$. With the molecular weight of 398 a $1.0 \mathrm{mM}$ concentration of glycopyrrolate would be equivalent to $0.398 \mathrm{mg}$ or $398 \mu \mathrm{g} \cdot \mathrm{ml}^{-1}$

Commonly used doses of glycopyrrolate in premedication range from $0.2-0.4 \mathrm{mg}$. Maximum plasma concentrations of glycopyrrolate in volunteers using a sensitive radio-immunoassay technique were about $35 \mathrm{ng} \cdot \mathrm{ml}^{-1}$ after $0.4 \mathrm{mg}$ IV (personal communication, C. J. Jones, A.H. Robins Co. Ltd., Horsham, England). Thus the $\mathrm{IC}_{50}$ of $1.0 \mathrm{mM}$ demonstrated in vitro is over 11,300 times the maximum plasma concentration in man after $0.4 \mathrm{mg}$ glycopyrrolate IV. Such concentrations would not be attained even with relatively larger doses (10$15 \mu \mathrm{g} \cdot \mathrm{kg}^{-1}$ ) of glycopyrrolate used at the time of antagonism of neuromuscular block. Glycopyrrolate has been used in many thousands of cases without any reports of prolonged action of succinylcholine or ester-type local anaesthetics.

The results Dr. Zsigmond and his colleagues have shown may be of academic interest but are of no clinical significance.

\section{Dr R.K. Mirakhur}

Dept. of Clinical Anaesthesia

Royal Victoria Hospital

Belfast, N. Ireland

\section{REFERENCES \\ 1 Zsigmond EK, Winnie AP, Barabas $E$, Wang $X Y$. The inhibitory effect of glycopyrrolate on human plasma cholinesterate. Can Anaesth Soc J 1985; 32: 20-2 \\ 2 Mirakhur RK, Dundee JW. Glycopyrrolate: pharmacology and clinical use. Anaesthesia, 1983, 1195-1204.}

\section{REPLY}

Dr. Mirakhur is correct in that the results of our studies have "academic interest," but he can not deny that the findings may also have clinical importance as we succinctly stated that: "Glycopyrrolate and atropine possess low inhibitory effect on human PChE, therefore it is unlikely that $P C h E$ in vivo would be inhibited to an extent that interferes with the hydrolysis of succinylcholine and/or local anaesthetics of the ester-type." Indeed, their experience concurs with our own observations that no clinically recognizable interactions take place between glycopyrrolate and succinylcholine. Nonetheless, only experiments involving the combination of glycopyrrolate with succinylcholine or procaine can scientifically answer this question.

Contrary to Dr. Mirakhur's claim that we extrapolated the in vitro inhibitory effects of glycopyrrolate to the clinical effects of succinylcholine and local anaesthetics. we are well aware of the studies of Foldes and Smith. Those studies showed that extrapolation to the in vivo antichalinesterase effect from its in vitro inhibitory effect is not permissible, since the $I_{50}$ values of other anticholinesterases used in the management of myastenia gravis demonstrated no correlation to their in vivo therapeutic effectiveness.

At the other extreme, hexafluorenium, which markedly inhibits $P C h E$ in vitro, causes a predictable and poten inhibition of the in vivo hydrolysis of succinylcholine and is, therefore, employed to prolong its effect for muscle paralysis. ${ }^{2}$ Moreover, in anticholinesterase poisoning. the large atropine doses required, e.g., 0.2-1.0 g daily, might lead to a marked in vivo PChE inhibition as predicted from its in vitro anticholinesterase effect also corroborated by Radic. ${ }^{3}$

PChE is present as "reserve cholinesterase" in other cholinergic transmission sites. ${ }^{4}$ Surprisingly, we find complete inhibition of the reserve cholinesterases by fractions of the $I_{50}$ of several anticholinesterases in the 
humain brain slices by histochemical methods. ${ }^{5}$ Based on these findings, and with the inadequate level of current knowledge on the actual number of active enzyme receptors and substrate concentrations in vivo at distinct cholinergic receptor sites, one cannot rule out the practical clinical value of this "academic" finding of a moderate PChE inhibitory effect.

Elemer K. Zsigmond, MD

Department of Anesthesia

University of Illinois

College of Medicine at Chicago, Chicago, Illinois

\section{REFERENCES}

1 Foldes FF, Smith JC. The inhibition of human cholinesterases with anticholinesterases used in the therapy of myasthenia gravis. Ann NY Acad Sci 1966, 135: 287.

2 Foldes FF, Molloy RE, Zsigmond EK, Zwartz JA. Hexafluorenium: its anticholinesterase and neuromuscular activity. J Pharmacol Exp Ther, 1960, 129: 400 .

3 Radic $Z$. Effect of atropine on esterases of human blood and pig liver. Abstract \#4 p. 43, VI. Balkan Biochemical and Biophysical Days, Plovdiv, April 15-19, 1985. Bulgaria.

4 Koelle WA, Koelle GB. The localization of external or functional acetylcholinesterase at the synapses in autonomic ganglia. Progr Brain Res 1971, 34, 371.

5 Foldes FF, Zsigmond EK, Foldes VM. The distribution of acetylcholinesterase and butyrylcholinesterase in the human brain. J Neurochem 1962, 9 : 559-72.

\section{Nuffield Department of Anaesthetics, Oxford}

To the Editor:

A scientific meeting will be held in Oxford from 23rd-25th July, 1987, to celebrate the Fiftieth Anniversary of the founding of the Nuffield Department of Anaesthetics. This meeting will follow the Second World Congress on the History of Anaesthesia, which is to be held in London from 20th23rd July, 1987.

Anaesthetists and others who have had connections with the department are invited to write to:

Nuffield Department of Anaesthetics (Dept. GP/87), Radliffe Infirmary,

Woodstock Road,

Oxford,

OX2 6HE,

England enclosing their full name and postal address so that they may be circulated with further particulars.

Professor M.K. Sykes

University of Oxford

\section{Transtracheal ventilation}

To the Editor:

I was interested to read the report by Ravussin and Freeman on transtracheal ventilation. ${ }^{1}$ Two points are worth raising, firstly that high frequency ventilation is not necessary to produce oxygenation. A simple hand-operated trigger device such as the Sanders bronchoscope injector can be used in most instances equally well ${ }^{2,3}$ and is more likely to be available in the emergency situation.

Secondly, in the interests of safety, I would like to stress the importance of a clear upper airway to allow the inflated gases to escape. This is best achieved with the patient's neck in the extended position (as for thyroidectomy). In my experience (in 60 cases) the surgeon can easily flex the head and neck while working on the lower jaw for example, resulting in obstruction of the gas escape pathway. Extra vigilance is necessary when using transtracheal ventilation, to prevent the occurrence of high pressure in the lower airways, leading to possible pneumothorax and emphysema.

\section{P.R. Layman MB CHB FFARCS \\ Department of Anaesthetics \\ John Radcliffe Hospital \\ Headington, Oxford}

\section{REFERENCES}

1 Ravussin P. Freeman J. A new catheter for transtracheal ventilation and resuscitation. Can Anacsth Soc J 1985; 32: 60-4.

2 Layman $P R$. Transtracheal ventilation in oral surgery. Annals of the Royal College of Surgeons 1983; 65: 318-20.

3 Layman PR. Bypassing a problem airway. Anaesthesia $1983 ; 38: 478-80$.

\section{REPLY}

We thank Dr. Layman for his letter. He points out two major aspects of great importance: (1) that when trans. tracheal jet ventilation is used, a clear upper airway is 
mandatory, because any gas injected into the trachea must be able to escape. This aspect is stressed in the discussion of our paper but it cannot be over-emphasized. (2) Transtracheal ventilation through a $13 G$ or $14 G$ catheter inserted into the trachea must be a jet-type ventilation. I entirely agree that high frequency jet ventilation ( $H F J V$ ) is not the only way to achieve good gas exchange. The Sanders Jetting Device or the Carden Jetting Device ${ }^{2}$ are both cheap, hand-operated and not cumbersome. Both devices can be plugged into a compressed oxygen supply system. I personally prefer the Carden Jetting Device because it has a pressure regula. tor (as in the HFJV ventilators) and thus the $405 \mathrm{kPa}$ (4 bar) pressure from the oxygen wall gas outlet can be adjusted according to the size and the condition of the patient.

The catheter described in our paper was first designed for easy, rapid use in an emergency but increasingly we use it for endoscopic and laser procedures involving the larynx or the very upper part of the trachea. Oedema often develops around the glottis after such procedures, and the catheter should be left in place for up to 12 hours, in case an obstruction of the glotris should develop. The catheter is very well tolerated by the patients even when they are fully recovered and conscious after anaesthesia.

P. Ravussin MD FMH

Department of Anaesthesia

Centre Hospitalier Universitaire Vaudois

Lausanne/Switzerland

REFERENCES

1 Sanders $R D$. Two ventilating attachments for bronchoscopes. Del Med J 1967; 39: 170-75.

2 Carden E, West HR. Further advances in anesthetic techniques for microlaryngeal surgery. Anesth Analg 1974; 53: 584-7. 